\title{
SOCIOCLIMAS, RIESGOS Y ORDENACIÓN DEL TERRITORIO EN LAS COMUNIDADES ANDINAS DEL DESIERTO DE ATACAMA
}

\author{
Hugo ROMERO ARAVENA y Dustyn OPAZO ALBARRÁN \\ Departamento de Geografía. Universidad de Chile. \\ hromero@uchilefau.cl, dustyn.opazo@gmail.com
}

\section{RESUMEN}

Mediante la integración de análisis digitales de imágenes satelitales, datos climáticos e investigación participativa se presenta el comportamiento de comunidades indígenas localizadas en la cordillera andina del Desierto de Atacama, uno de los más áridos del mundo, que han habitado estos paisajes por más de 10.000 años, desarrollando estrategias de mitigación y adaptación ante cambios y variabilidades climáticos, que incluyen la aplicación de un conjunto de conocimientos locales referidos a la predicción, enfrentamiento y reconstrucción ante eventos extremos tales como sequías, inundaciones, ondas de calor y de frío. La concepción cultural y división social de los riesgos climáticos a escala de la comunidad andina corresponde a prácticas productivas, modos de vida y representaciones simbólicas de los climas locales o socioclimas que integran las amenazas naturales a formas de resiliencia contextoespecíficas, destacando la ocupación sistemática y simultánea de los pisos ecológicos, la comunidad translocalizada y la reconfiguración de órdenes territoriales ad-hoc.

Palabras claves: socioclimas, comunidades indígenas, desierto de Atacama,topoclimatología, investigación participativa.

\begin{abstract}
Using integrated digital analysis of satellite images, climatic data and participatory research described the behavior of indigenous communities located in the Andes mountain chain in the Atacama Desert, one of the driest in the world, who have inhabited these landscapes for more than 10,000 years, developing strategies for mitigation and adaptation to climate change and variability, including the implementation of a set of local knowledge concerning the prediction, confrontation and reconstruction to extreme events such as droughts, floods, heat and cold waves. The cultural conception and social division of climate risks at the scale of the Andean community correspond to productive practices, households and symbolic representations of local climates or socioclimates that integrate natural hazards to forms of context-specific resilience, highlighting the systematic and simultaneous occupation of ecological belts, translocated communities and ad-hoc reconfiguration of territorial management.
\end{abstract}

Keywords: socioclimates, indigenous communities, Atacama Desert, topoclimatology, participatory research.

\section{INTRODUCCIÓN}

El Desierto de Atacama es probablemente el más árido del mundo. Los promedios anuales de sus lluvias solo alcanzan unas décimas de milímetros de agua caída 
en las estaciones litorales y están totalmente ausentes en las localidades del interior del país. Bajo tales circunstancias debería corresponder a un territorio totalmente deshabitado, pero la Cordillera de los Andes, que lo limita por el oriente, localiza "torres de agua" (fig. 1) que al concentrar las precipitaciones permiten que los flujos superficiales y subterráneos provean de los recursos hídricos necesarios para el desarrollo de comunidades ecológicas, ciudades, minas, cultivos y ganados, que se han constituido en la actualidad y a lo largo de la historia de Chile, en una de las principales fuentes de riqueza y bienestar de un país que exhibe los mayores niveles de ingresos económicos e indicadores de desarrollo humano y as menores tasas de pobreza de la región latinoamericana. La comprensión, control y gestión de las condiciones geográficas de las cuencas andinas del Desierto de Atacama (fig. 2) se constituye en el principal objetivo ambiental, político, cultural, social y económico de las comunidades que allí habitan desde los tiempos del imperio incásico. La escasez, irregularidad e incertidumbre de las lluvias que se registran en la cordillera andina dependen grandemente del comportamiento del Monzón Amazónico, que a su vez se relaciona especialmente con la fortaleza, magnitud y posición de la Alta de Bolivia y de las interacciones océano-atmósfera asociadas a los eventos El Niño-Oscilación del Sur (ENOS), Oscilación Decadal del Pacífico (ODP) y Convergencia Antártica (CA) (Romero et al., 2011; Mendonca et al, 2014). El riesgo de las sequías prolongadas, la eventual ocurrencia de lluvias abundantes que causan inundaciones y aluviones, la recurrencia de ondas de frío (acompañadas de nevazones y fuertes vientos), configuran paisajes esencialmente amenazantes cuyo enfrentamiento exige altos grados de resiliencia de los sistemas socio-ecológicos (Romero et al., 2013; Sarricolea y Romero, 2015).

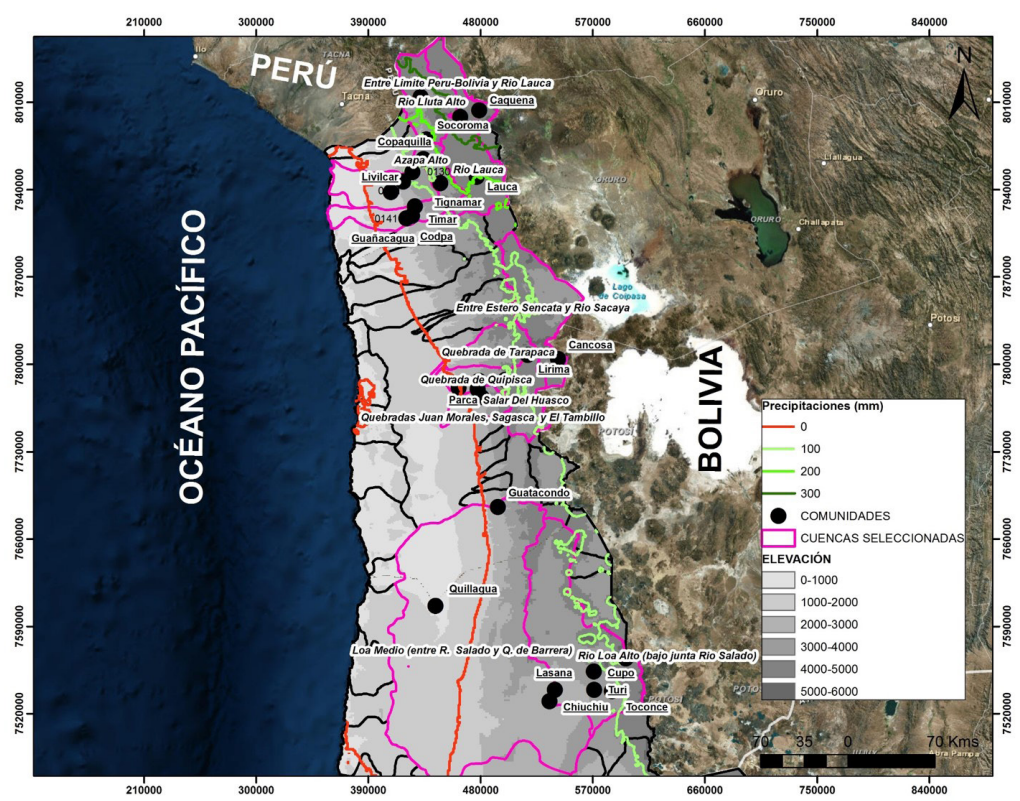

Figura 1. Comunidades y cuencas seleccionadas como áreas de estudio en el Desierto de Atacama, indicando alturas y precipitaciones medias anuales. Elaboración propia 


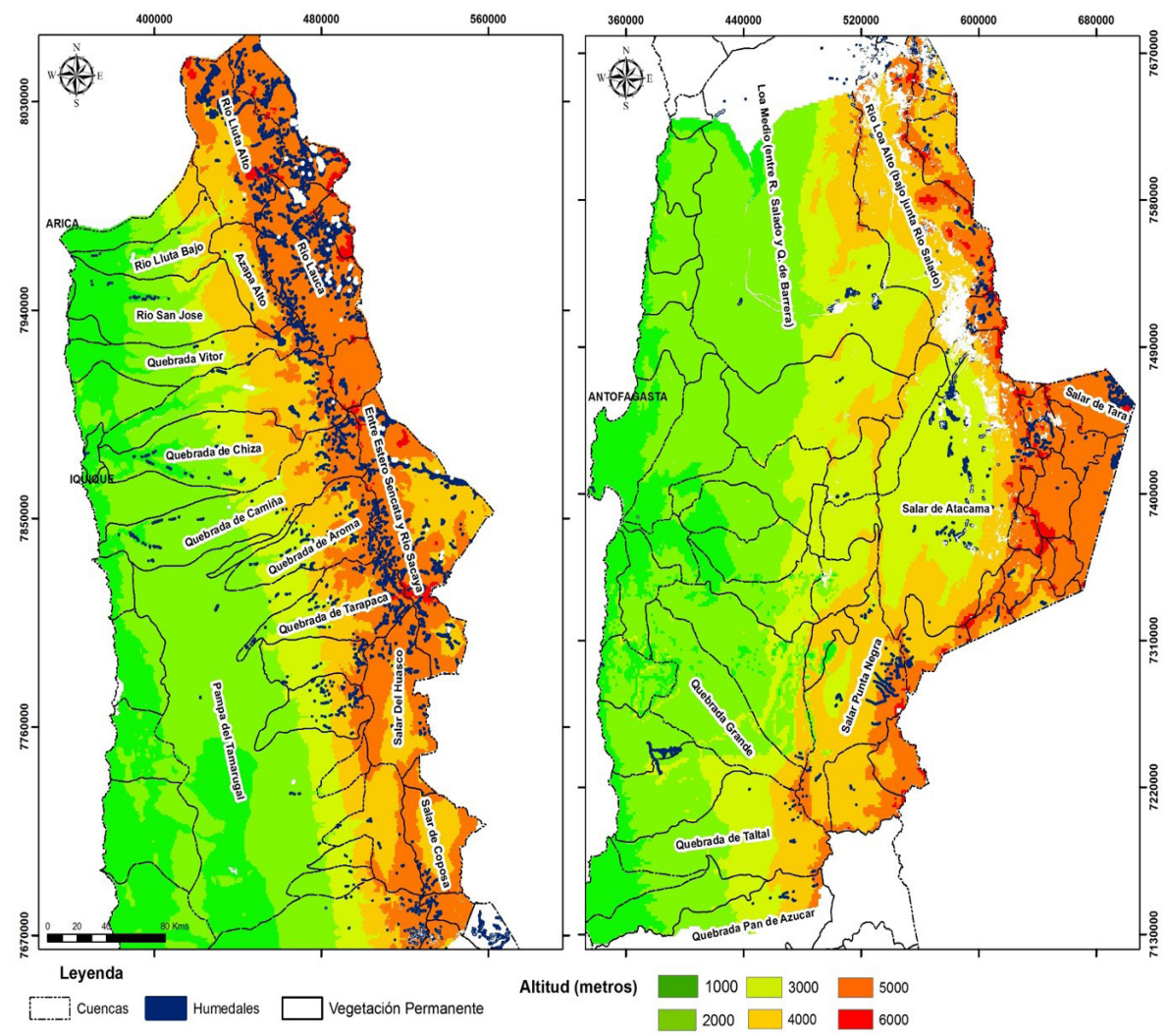

Figura 2. Organización territorial sobre la base de cuencas ambientales, humedales y pisos de altura en el Desierto de Atacama. Elaboración propia

Mientras los modelos de cambio climático pronostican un importante desecamiento en la mayor parte de la Cordillera de los Andes, se advierten significativas variabilidades espacio temporales relacionadas con la topoclimatología de los altiplanos, sistemas de laderas y valles que caracterizan complejos orográficos de gran magnitud y elevado dinamismo ecológico, geomorfológico e hidrológico, cuya comprensión y gestión requeriría conocimientos científicos que no se encuentran disponibles (Romero et al., 2013). Existe una gran variedad en los climas de los lugares, que depende especialmente del alcance de las influencias amazónicas, de la distribución de los pisos ecológicos controlados por la altura y de las exposiciones de las montañas ante las masas de aire cargadas de humedad (Mendonca et al., 2014). Los más recientes desastres hidrometeorológicos como los aluviones de marzo de 2012 y principalmente de marzo de 2015, han demostrado el desconocimiento de los topoclimas, lo que se está intentando resolver con la instalación de redes de observación ubicados sobre $3.000 \mathrm{~m}$. de altitud, el análisis digital e interpretación de imágenes satelitales y mediante investigaciones participativas que intentan vincular dichos datos con los conocimientos locales de que dispone un conjunto de comunidades localizadas en los valles y altiplanos andinos (fig.1). 


\section{MÉTODOS}

Dada la complejidad de los topoclimas, para su análisis e interpretación se están utilizando en forma integrada informaciones proporcionadas por estaciones meteorológicas instaladas en los sectores altos de las cuencas seleccionadas, análisis digitales de imágenes LANDSAT 5, que representan la distribución de las temperaturas superficiales de emisión, verdor vegetal y humedad de los suelos y métodos cualitativos que incluyen investigaciones participativas que comprenden conversaciones y entrevistas en profundidad con representantes de las comunidades indígenas andinas.

\section{RESULTADOS}

El conocimiento local de los climas regionales y de los mecanismos de mitigación y adaptación ante las variabilidades han sido fundamentales para la sobrevivencia de las comunidades locales y ello ha dependido de sistemas de información cuyos objetos y datos, no obstante, son diferentes a los aportados por la ciencia moderna, pero no por ello menos significativos.

\subsection{Topoclimatología andina}

Las figuras 3 y 4 presentan la comparación de rasgos topoclimáticos cuyo comportamiento espacial y temporal ha sido obtenido del procesamiento de imágenes satelitales LANDSAT TM correspondientes a los meses del verano climatológico (enero y febrero), que constituyen la estación lluviosa en el régimen amazónico que alcanza a las montañas andinas del altiplano chileno que bordea por el oriente el Desierto de Atacama. Se han seleccionado imágenes de los años 1989 y 2001 que corresponden al año más seco el primero y más lluvioso el último, con la finalidad de apreciar los cambios más relevantes que experimentan los paisajes.

Respecto a la distribución de las temperaturas superficiales se observan franjas altitudinales que conforman los cinturones ecológicos que han asentado a las comunidades biológicas y culturales. La más occidental da cuenta de las planicies y farellones costeros por los cuáles el relieve se eleva bruscamente desde el nivel del mar hacia una depresión intermedia cuya altura supera los $1.000 \mathrm{~m}$. y que conforma la llamada "pampa" o desierto interior, caracterizada por la total sequedad y por la acumulación de elevadas temperaturas. Las influencias oceánicas consiguen penetrar a través de quebradas y favorecen el registro de oscilaciones térmicas reducidas, alta humedad atmosférica y presencia habitual de neblinas costeras, llamadas localmente como "camanchacas" (Romero, 1985). El clima seco, cálido y de alta oscilación térmica diaria de las "pampas", solo se ve interrumpido por "islas de frescor" que resultan de elevaciones locales y de la presencia excepcional de bosques de prosopis (tamarugos) en la llamada "Pampa del Tamarugal", alimentados por el surgimiento de aguas subterráneas provenientes de la cordillera andina. Hacia el oriente, la altura aumenta gradualmente, generando una precordillera que fluctúa entre 2000 y 3000 $\mathrm{m}$ y cuya temperatura de emisión superficial varía entre 37 y $47^{\circ} \mathrm{C}$ y que culmina en un primer cordón montañoso que registra entre -25 y $-67^{\circ} \mathrm{C}$. Continuando hacia el oriente, comienzan a desarrollarse los climas altiplánicos, que generan condiciones topoclimáticas más favorables para las comunidades biológicas y humanas, salvo las áreas dónde se localizan las montañas más elevadas y los cordones volcánicos. 

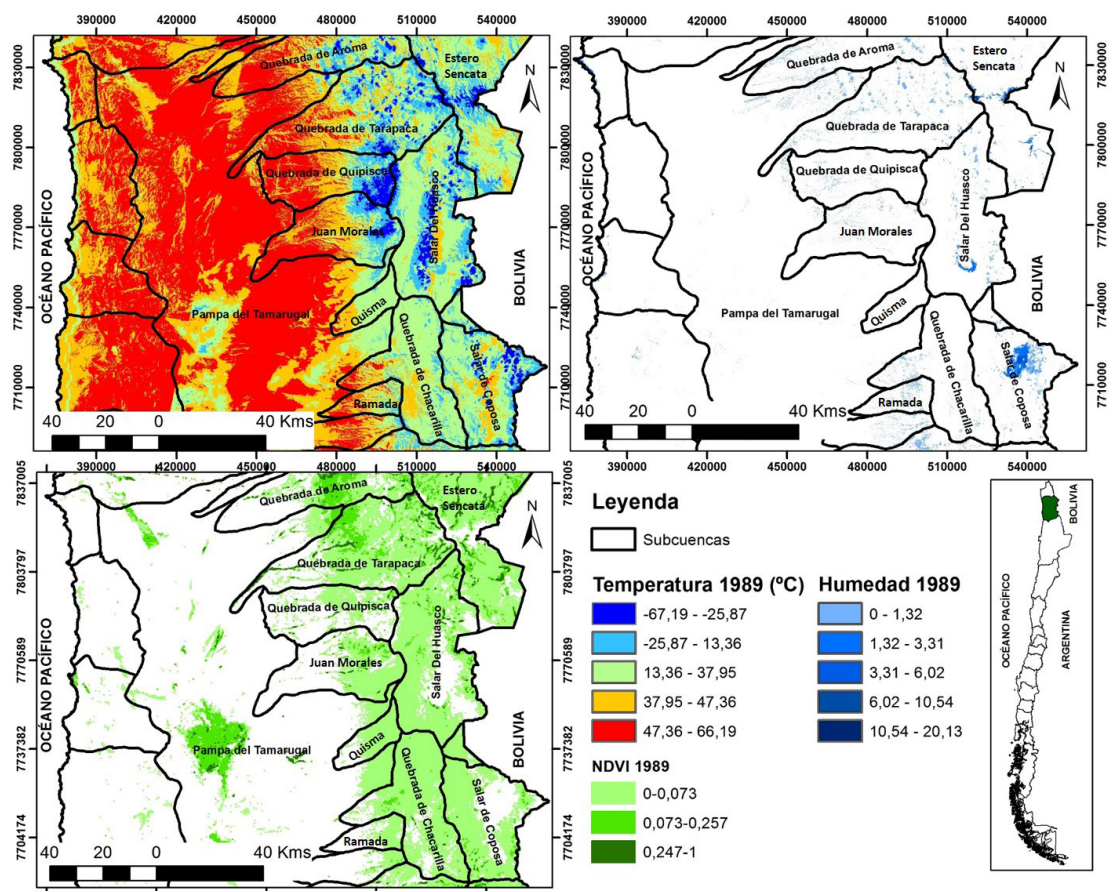

Figura 3. Comparación de la distribución de las temperaturas superficiales de emisión, indices vegetales y humedad del suelo en comunidades andinas seleccionadas de la región de Tarapacá en 1989. Elaboración propia.

Durante el año lluvioso de 2001, se mantiene la división entre las franjas costera, "pampa", precordillera, cordillera y altiplanos, pero los valores de temperatura son más elevados como consecuencia de la mayor humedad y vegetación que cubre los suelos. Las temperaturas mínimas extremas registradas en el año seco no se observan en el año húmedo de la serie, lo que favorece la ecología local.

Respecto a la distribución espacial de la humedad de los suelos, se puede apreciar la absoluta sequedad que caracteriza al Desierto de Atacama, registrándose durante 1989 la presencia excepcional de algunos pixeles húmedos aislados en las quebradas de Tarapacá y Aroma, que corresponden a humedales y arroyos fragmentados. Los dos grandes cuerpos de agua del altiplano, los salares de Huasco y Coposa, se ven disminuidos y fragmentados en sus superficies hídricas, lo que manifiesta su extraordinaria sensibilidad ante los volúmenes de precipitaciones y la incertidumbre sobre la disponibilidad de agua para brindar sus servicios ambientales. Durante el año lluvioso de 2001 se advierte como el curso superior de la quebrada de Tarapacá, que nace en la cuenca altiplánica del Estero Sencata, se transforma desde un conjunto de pixeles húmedos aislados en un curso continuo de agua, que no obstante, desaparece prontamente aguas abajo. Los salares de Huasco y Coposa se consolidan como lagunas durante los períodos lluviosos, adquiriendo toda su importancia como ecosistemas biológicos y oasis culturales, ambos hechos excepcionales en el borde de uno de los paisajes más áridos del planeta. 

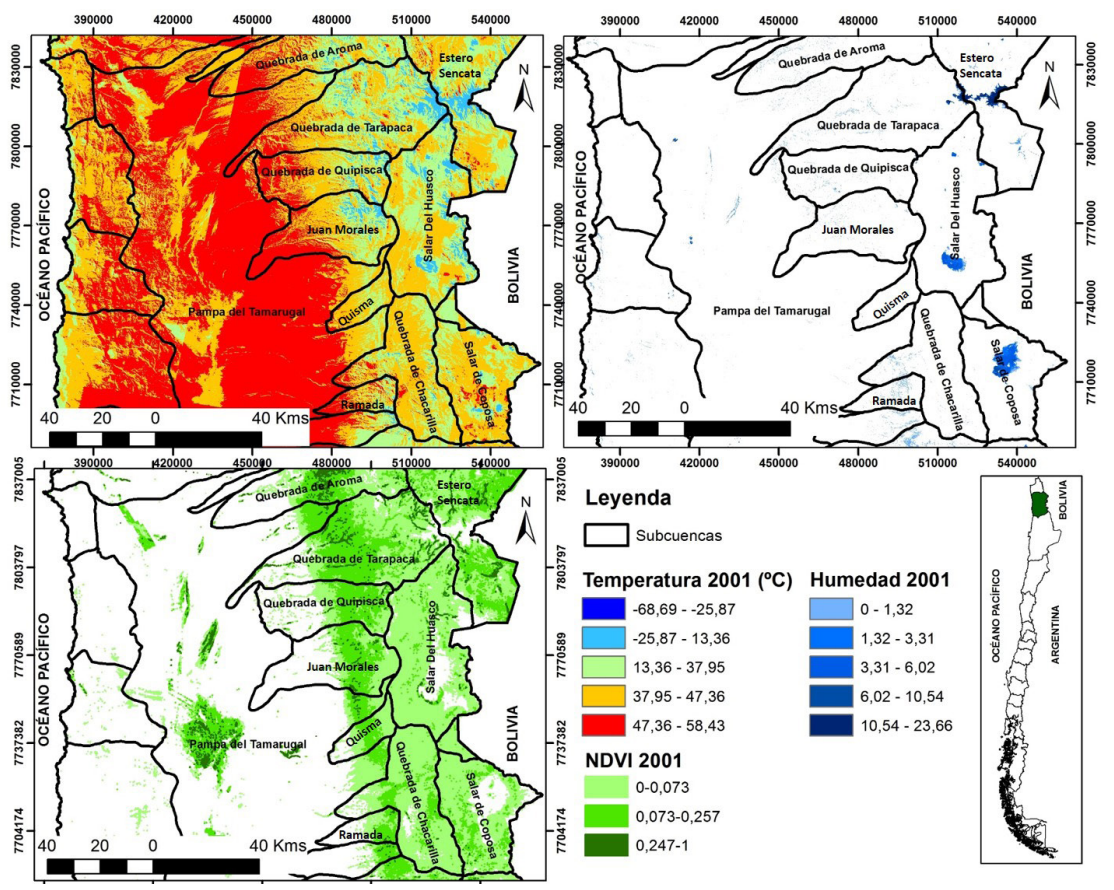

Figura 4. Comparación de la distribución de las temperaturas superficiales de emisión, indices vegetales y humedad del suelo en comunidades andinas seleccionadas de la región de Tarapacá en 2001. Elaboración propia.

Bajo tales condiciones climáticas restrictivas para los paisajes naturales y culturales, la vegetación solo se advierte en las franjas más frías de las precordilleras y altiplanos que caracterizan los bosques y matorrales de los cursos superiores de las cuencas, mientras que las estepas y pajonales se generalizan en las tierras más altas, controlando la existencia de pastos y con ello, la presencia de ganado auquénido que sirve de sustento a las comunidades pastoriles. Fuera del dominio cordillerano, durante el año seco, en el desierto interior de las "pampas" la vegetación se restringe a oasis como los ocupados por la Pampa del Tamarugal y algunos sectores de quebradas que concentran la emergencia de aguas subterráneas que ingresan al sistema en las tierras altas, constituyendo otra serie de ecosistemas y sociosistemas de extraordinaria vulnerabilidad. Durante el año lluvioso, se observa el aumento de los índices de verdor debido a la mayor densidad y continuidad espacial de la vegetación, especialmente sobre la región precordillerana, área que comanda la organización de los circuitos de transhumancia de las comunidades pastoriles aymaras.

\subsection{Climatología cultural y socioclimas andinos}

Para Tadaki et al. (2012), "Las actividades humanas alteran e interactúan con la física y química de la atmósfera a través de las escalas global-local. Modificaciones humanas de los paisajes y los biomas corren de diferentes maneras a través del espacio y tiempo, y los actores humanos y las instituciones proponen y coordinan 
estructuras metafísicas para vincular observaciones e ideas acerca del mundo natural" (547). La tesis central de Tadaki et al. (2012) es que el giro cultural de la geografía física debe ser presidido por el reconocimiento de que esta disciplina ha sido siempre cultural y que sus practicantes e instituciones proveen de un sistema significativo a través del cual "el orden es comunicado, reproducido, experimentado y explorado" (Williams, 1981, cit. 550).

Las comunidades ancestrales han habitado y gestionado por miles de años estos paisajes lo que ha requerido conocimientos e informaciones que les han permitido adoptar decisiones para mitigar los cambios de corto plazo y adaptarse a los de plazo mediano y largo. La consideración de estos conocimientos requiere de un amplio proceso de diálogo (Gaillard and Mercer, 2012) entre los científicos y los habitantes indígenas, entre los agentes externos e internos de la comunidad y entre las decisiones adoptadas desde abajo hacia arriba y desde arriba hacia abajo. Los vientos, las nubes, la lluvia, los escurrimientos superficiales y subterráneos de agua, el almacenamiento de ésta en el suelo y en los vegetales, la fauna y flora y desde luego, las comunidades humanas y no-humanas constituyen un sistema holístico de múltiples interacciones recíprocas manifestadas en flujos materiales y simbólicos. Así entendido, el clima es un hecho socionatural en la medida que no significa solo un evento o fenómeno atmosférico, sino que trata de un constructo cultural que asocia y ordena las fases del ciclo climático, relacionándolas con acciones humanas y divinas específicas, en un sistema de conocimientos que no separa los hechos físicos de los metafísicos o la vida del tiempo y del espacio (Boelens, 2014). De esta forma, la condensación y las precipitaciones ocurren por voluntad de los dioses de las montañas, que controlan a su vez a las divinidades del viento y las nubes, y finalmente el escurrimiento de las aguas, a través de otras tantas deidades. Las respuestas de los dioses son proporcionales a la fe y sacrificios que acompañan las rogativas presentadas por los comuneros en ceremonias especialmente convocadas antes que comience la estación de las lluvias. Mientras la quema de incienso vincula las rogativas de los comuneros directamente con las nubes y las montañas al viajar por los aires, el vaciamiento de depósitos con agua de mar sobre los arroyos de las laderas, pretende acelerar las fases de evaporación-condensación-precipitación, al mismo tiempo que la sangre de los animales sacrificados aumenta el escurrimiento superficial de las aguas.

El socioclima vincula conocimientos, valores, prácticas y gestión de los territorios, que finalmente contribuyen a la identidad comunitaria, que comprende elementos y significados físicos, abstractos y sobrenaturales generando una representación de carácter híbrido que también alcanza al agua a través de los territorios y redes hidrosociales, así como a la totalidad de los actantes ecológicos, destacando especialmente el carácter de los animales domésticos, considerados integrantes de las familias. El estudio de los socioclimas se realiza a través de investigaciones participativas mediante entrevistas en profundidad y conversaciones practicadas en forma sistemática entre los investigadores y los miembros de la comunidad. En este caso, los hallazgos presentados han sido recogidos en las comunidades de Lirima, Cancosa, Copaquilla y Salar del Huasco, todos lugares de residencia de comunidades aymaras situadas sobre $3.000 \mathrm{~m}$. de altura, en los bordes de humedales y arroyos, por Basaure (2015). La organización del sistema socioecológico posiciona a todos sus integrantes en igualdad de condiciones y exige una permanente conversación y respetabilidad mutua entre la 
naturaleza y la sociedad de alto valor conservacionista. Los habitantes locales deben respeto permanente a los dioses que encarnan al clima y las aguas, destacando por su importancia, el monte más alto de la localidad, donde se concentran los flujos de humedad provenientes del océano y del interior. Las peticiones de los comuneros, principalmente relacionadas con la ocurrencia de lluvias abundantes, suaves, bien repartidas en el tiempo y el espacio, que aseguren la disponibilidad de agua, pastos y alimentos todo el año, deben ser expuestas en ceremonias públicas, donde los sabios locales los transmiten hacia las alturas de las montañas. Producidas las lluvias, es necesario aumentar su fluidez aguas abajo por lo que se sacrifican corderos y llamas para que el vertido de su sangre incremente los caudales, al mismo tiempo que la comunidad implora sobre su persistencia y su fusión con la "madre tierra" (pachamama), mediante bailes y carnavales, para asegurar la fertilidad de los suelos y el abastecimiento alimenticio.

Como la variabilidad y los cambios climáticos siguen registrándose como parte de los ciclos normales, la comunidad debe adoptar acciones sociales de mitigación y adaptación para lo cual es indispensable disponer de un sistema de pronósticos. Los habitantes locales identifican principalmente a las sequías, ondas de frío (debido al fuerte viento y las bajas temperaturas), los aluviones y los adelantos o retrasos de las estaciones del año (lluviosa o seca) como las principales amenazas climáticas. Estas variaciones son predichas mediante la observación rigurosa del comportamiento de diversos componentes de la flora y fauna de los paisajes de los lugares ocupados por la comunidad. El momento del florecimiento y fructificación de pastos y cactáceas en los alrededores de los humedales y en las estepas altoandinas son reconocidos como hechos anticipatorios de las características climáticas del verano próximo, como también los son el aparecimiento de determinados insectos, la abundancia de batracios y la cantidad, color y forma de volar de los flamencos que nidifican en los cuerpos de agua (Basaure, 2015). El conocimiento local sobre la ocurrencia de los eventos extremos, sin embargo, no los relaciona causalmente con eventuales procesos de cambio climático sino que con las dificultades crecientes que debe enfrentar la comunidad para convocar a sus miembros a participar en forma masiva en las rogativas, debido a que la mayor parte ha emigrado hacia las ciudades o bien por el envejecimiento de sus poblaciones. Para ellos, sería necesario no solo aumentar el número de participantes y la frecuencia de las ceremonias sino que además exigirles a éstos mayores niveles de fe en sus actos y rogativas, así como perfeccionar los ritos practicados: invitar a un sabio más poderoso desde la vecina Bolivia, sacrificar más animales y especialmente, realizar las ceremonias en forma completa, como lo hacían los abuelos. La emigración y los cambios de modos de vida han resentido la relevancia de las ceremonias y con ello disminuido la capacidad de interacción con las divinidades, componente fundamental de los socioclimas.

\section{CONCLUSIONES}

Este trabajo ilustra sobre desafíos y resultados preliminares obtenidos por una investigación climatológica concebida como un diálogo entre conocimientos científicos universales y locales vernaculares, que sintetiza procesos multiescalares y que se expresa culturalmente a través de acciones materiales, simbólicas y metafísicas ejecutadas por comunidades indígenas que han sobrevivido en parajes extremos por 
miles de años. Los socioclimas se encuentran entre los conceptos híbridos que responden a una perspectiva de análisis multidisciplinario que requiere de aproximaciones metodológicas que aúnan procedimientos cuantitativos y cualitativos en sus estrategias de investigación. En la actualidad, se intenta relacionar como unidades geográficas de análisis los lugares donde habitan las comunidades, sus particularidades topoclimáticas -especialmente montañas, cuencas y altiplanos-, los datos registrados en estaciones meteorológicas fijas y móviles, imágenes satelitales, y principalmente conocimientos, interpretaciones y gestiones que ejecutan los habitantes locales, pueblos indígenas andinos que pueden enseñarnos cómo administrar el territorio si se trata de lograr procesos de mitigación y adaptación ante los cambios y variabilidades climáticas. Si bien estas comunidades han asegurado su sobrevivencia por miles de años, en la actualidad amenazan con desaparecer como consecuencia de equivocados procedimientos de construcción del conocimiento y de formulación y aplicación de los planes de desarrollo socioeconómico en territorios socio-ecológicos específicos.

\section{AGRADECIMIENTOS}

Este artículo presenta resultados obtenidos en el Proyecto Regular del Fondo Nacional de Investigaciones Científicas y Tecnológicas de Chile (FONDECYT), $\mathrm{N}^{\circ} 1150701$, a quiénes se agradece su colaboración.

\section{REFERENCIAS}

Basaure, M.F. (2015). Población Aymara y agua en los humedales de la Comuna de Pica. Región de Tarapacá, Chile. Memoria de Título para optar al Título de Antropóloga Social. Departamento de Antropología, Universidad de Chile. Recuperado de: http://repositorio.uchile.cl/handle/2250/137487

Boelens, R. (2014). Cultural politics and the hydrosocial cycle: Water, power and identity in the Andean highlands. Geoforum, 57, 234-247. DOI: 10.1016/j. geoforum.2013.02.008

Mendonca, M., Romero, H. y Opazo, D. (2014). Análise multiescalar para a comprenssao de causas e consequencias da variabilidade climática na América do Sul. Experimentos em Climatología Geográfica. Coordinadores: Charlei Aparecido de Silva, Edson Soares Fialho e Ercilio Torres Steinke. Asociación Brasileña de Climatología Geográfica, pp. 271-290. DOI: http://dx.doi. org/10.5380/abclima.v14i1

Romero, H. (1985). Geografía de los Climas, Tomo IX de la Colección Geografía de Chile. Instituto Geográfico Militar de Chile. Santiago de Chile, 250 p.

Romero, H. (2009). Comodificación, exclusión y falta de justicia ambiental. Globalización y territorio en América Latina. Editores Delgado Mahecha, y Cristancho Garrido. Biblioteca Abierta, Colección General, serie Geografía. Universidad Nacional de Colombia, Facultad de Ciencias Humanas, Departamento de Geografía, pp.243-291. Recuperado en http://www.repositorio.uchile.cl/ handle/2250/118085.

Romero, H., Méndez, M., \& Smith, P. (2012). Mining development and environmental injustice in the Atacama Desert of Northern Chile. Environmental Justice, 5(2), 70-76. DOI:10.1089/env.2011.0017. 
Romero,H., Mendonça, M., Méndez, M.y Smith,P.(2011). Multiescalaridad, relaciones espaciales y desafíos ecológico-sociales de la climatología sudamericana. El caso del desierto de Atacama. Revista Brasileira de Climatología. Año 7.Vol. 8. Pp.729. DOI: http://dx.doi.org/10.5380/abclima.v9i0.

Romero, Hugo, Smith, Pamela, Mendonça, Magaly, \& Méndez, Manuel. (2013). Macro y mesoclimas del altiplano andino y desierto de Atacama: desafíos y estrategias de adaptación social ante su variabilidad. Revista de geografía Norte Grande, (55), 19-41. https://dx.doi.org/10.4067/S0718-34022013000200003

Romero, H., Smith, P. and Vásquez, A. (2009). Global Changes and economic globalization in The Andes. Challenges for developing nations. Global Change and Sustainable Development in Mountain Regions. Editors: Psenner, R., Lackner, R., Borsdorf, A. Innsbruck University Press, University of Innsbruck, Vice-rectorate for Research, Austria.pp.71-95. Recuperado de https://www.uibk. ac.at/alpinerraum/publications/vol7/romero.pdf.

Romero Aravena, H; Sarricolea Espinoza, P; (2015). Variabilidad y cambios climáticos observados y esperados en el Altiplano del norte de Chile. Revista de Geografía Norte Grande, () 169-183. Recuperado de http://www.redalyc.org/ articulo.oa? $\mathrm{id}=30042325010$

Tadaki, M., Salmond, J., Le Heron, R. and Brierley, G. (2012), Nature, culture, and the work of physical geography. Transactions of the Institute of British Geographers, 37: 547-562. doi: 10.1111/j.1475-5661.2011.00495. 